\title{
Lung Maturation in Fetuses of Diabetic Rats
}

\author{
OLOF TYDEN, CHRISTIAN BERNE. AND ULF ERIKSSON ${ }^{(A N)}$ \\ Department of Obstetrics and Ginaecologv. Departments of Internal Medicine and Medical Cell Biologi: \\ University of Uppsala, Uppsala. Sweden
}

\begin{abstract}
Summary
Pulmonary maturation in diabetic pregnancy has been studied in the 20-day-old fetuses of manifest diabetic rats. The animals were either untreated or treated with insulin. The diabetic state was induced by a single IV injection of streptozotocin given about 2 wk before the onset of pregnancy. The biosynthesis of lung surfactant was estimated by monitoring the rate of incorporation of $\mid$ methy $/ l^{3} \mathrm{H} \mid$ choline into phosphatidylcholine and lysophosphatidylcholine in fetal lung slices.

In the untreated group, the biosynthesis of both phosphatidylcholine and lysophosphatidylcholine were decreased in the fetal lung. Insulin treatment abolished the decrease in the phosphatidylcholine biosynthesis, whereas the lysophosphatidylcholine biosynthesis reamined depressed. Light and transmission electron microscopical studies indicated a delayed pulmonary maturation in the untreated offspring accompanied by a decreased cytoplasmic content of glycogen in the alveolar epithelial cells.
\end{abstract}

\section{Speculation}

It is suggested that, in diabetic pregnancy, respiratory distress syndrome becomes manifest after a diminished availability of surface-active dipalmitic phosphatidylcholine in the fetal lung, resulting from a specific inhibition of the lysophosphatidylcholine pathway.

Respiratory distress syndrome (RDS) is a major cause of neonatal morbidity and mortality in diabetic pregnancy (39). RDS is the clinical manifestation of pulmonary immaturity. The maturation process involves a steroid-mediated increase in the biosynthesis of various surface-active phospholipids $(2,14,15,17,36)$, especially dipalmitic phosphatidylcholine (PC) and phosphatidylglycerol (PG), in the type II cell of the alveolar lining $(19,29)$. In these cells, the surface-active material formed is temporarily stored in the lamellar bodies before extrusion to the extracellular space $(9.28)$. In all species studied, the major pathway of PC biosynthesis involves the incorporation of CDP-choline into diglyceride (11, 20 ). This pathway accounts for about $97 \%$ of the total PC formed in the fetal rat lung. The biosynthesis of $P C$ reaches a peak 2 days before birth $(34,44)$ at a time when the glycogen content of the type II cell is declining in a manner inversely proportional to the phospholipid content of the cell $(5,26,34)$. In diabetic pregnancy, this maturation process is somehow disturbed, possibly as a result of alterations in the insulin level in the fetal circulation. However, there are conflicting reports concerning the effect of insulin on the biosynthesis of PC $(10,41)$. Recently, the importance of hyperinsulinemia for the development of RDS in diabetic pregnancy has been questioned because no increase in cord blood C-peptide levels could be detected in human offspring subsequently developing RDS (42). The precise cause of the delayed fetal pulmonary maturation in diabetic pregnancy therefore remains unresolved.

The aim of this investigation was to study, in biochemical and morphologic terms, pulmonary maturation in offspring of rats with severe streptozotocin-induced diabetes ( $c f$. Ref. 12).

\section{MATERIALS AND METHODS}

Manifest diabetes (MD) was induced in 3-month-old virgin Sprague-Dawley rats by a single IV injection of streptozotocin (kindly donated by W. E. Dulin, Upjohn Co.. Kalamazoo, MI) at a dose of $45 \mathrm{mg} / \mathrm{kg}$ body weight. Animals with a nonfasting blood glucose concentration of more than 22 mmoles/liter one wk after the injection were classified as MD. Treatment with bovine Novo Ultralente Insulin (Novo Co.. Copenhagen, Denmark) was commenced in about one-half of the diabetic animals. The dose, ranging from 2 to 8 units/day, was adjusted according to the blood glucose concentration, which was determined twice a wk. Weightmatched normal rats $(\mathrm{N})$ of the same age served as controls. The animals were mated 2 to $4 \mathrm{wk}$ after the streptozotocin treatment. and daily vaginal smears were examined for the presence of sperm. The duration of pregnancy could therefore be determined with an accuracy of $\pm 6 \mathrm{hr}$.

\section{BIOCHEMICAL. STUDIES}

On gestational day 20 , the rats were killed by a blow on the neck, and the fetuses were quickly dissected from the uterus and decapitated before any spontaneous breathing had occurred. The right lungs were excised and pooled litterwise in Hanks' solution. Maternal and fetal blood was collected for determination of serum insulin (23) and glucose concentrations (Beckman Glucose Analyzer 2: Beckman Inc., Fullerton, CA). To determine the rate of choline incorporation into $\mathrm{PC}$ and lysophosphatidylcholine (LPC), the pooled lungs were chopped with a pair of scissors into pieces of approximately $1 \mathrm{~mm}^{3}$ and transferred into a vessel containing $100 \mu \mathrm{l}$ Krebs-Ringer bicarbonate buffer $(\mathrm{pH} 7.6)$ equilibrated with $\mathrm{O}_{2}: \mathrm{CO} .2(95 \%: 5 \%)$ and choline chloride $(0.0 \mathrm{l}$ mmole/ liter). After a 10 -min preincubation period in a shaking water bath at $+38^{\circ} \mathrm{C}$. the medium was changed. and $10 \mu \mathrm{Ci}$ of $\left[{ }^{3} \mathrm{H}\right]$ methylcholine chloride (specific activity, $6.4 \mathrm{Ci} / \mathrm{mmole}$ ) were added. The incorporation of label was terminated after $90 \mathrm{~min}$ by addition of $200 \mu \mathrm{l} 1 \mathrm{mM}$ choline chloride, and the incubation was extended for a further $10 \mathrm{~min}$ to dilute the radioactivity. The lung samples were subsequently washed twice in a salt solution (16) and sonicated for $10 \mathrm{sec}$ (Ultrasonic disintegrator; $60 \mathrm{~W}$. MSE. London. United Kingdom) in $150 \mu \mathrm{l}$ of the wash solution. Duplicate $|0-\mu|$ samples of the homogenate were removed for determination of DNA content. The lipids of the remaining homogenate were then extracted for $2 \mathrm{hr}$ with chloroform:methanol (2:1). After four washings to remove water-soluble radioactivity (16), $30 \mu \mathrm{l}$ of a solution of mixed egg yolk phospholipids $(24 \mathrm{mg} / \mathrm{ml})$ (Vitrum AB. Stockholm, Sweden) was added as a carrier. The lower phase, containing the phospholipids, was evaporated to dryness under a stream of pure nitrogen. The extracts were then dissolved in 100 $\mu \mathrm{l}$ of chloroform:methanol $(2: 1)$, and $40 \mu \mathrm{l}$ were spotted on precoated plates of Silica Gel G (E. Merck A. G., Darmstadt, Germany). The phospholipids were separated in a solvent system of chloroform:methanol:acetic acid:0.1 $\mathrm{M} \mathrm{Na}_{2} \mathrm{CO}_{3}$ in water (50:25: $7: 3$ by volume) (40). The phospholipid spots were identified in ultraviolet light after spraying the plates with $2^{\prime} 7^{\prime}$-dichlorofluorescein $(0.2 \mathrm{mg} / \mathrm{ml})$. The spots corresponding to the PC and LPC markers were scraped off into scintillation vials containing $0.5 \mathrm{ml}$ 
methanol (3) and $10 \mathrm{ml}$ of a toluene-based scintillation solution $15 \mathrm{~g}$ 2.5-diphenyloxazole:0.05 g 1.4-bis[4-methyl-5-phenyloxazol2-yl]benzene: $1000 \mathrm{ml}$ toluene). Standards, containing $5 \mu \mathrm{l}$ of the radioactive incubation medium, were used for the determination of the specific activity of labeled choline. The radioactivity was measured in a Packard Scintillator Counter 3255 (Packard Instrument Co. Inc., Downers Grove, IL), and dpm were determined after correction for quenching according to the channels ratio method. The DNA content of the lung homogenates was estimated according to the method of Kissane and Robins (30) as modified by Hinegardner (25). The fluorescence was measured in a Farrand Ratio Fluorometer (Farrand Optical Co., Mt. Vernon, NY). The rate of incorporation of choline into phospholipids was expressed as pmoles $/ \mu \mathrm{g}$ DNA per hr. Statistical calculations in the offspring were made on the basis of numbers $(n)$ of litters. Probabilities $(P)$ of chance differences between the groups were estimated according to Student's two-tailed $t$ test.

\section{MORPHOLOGIC STUDIES}

Three fetuses from each experimental group, but from different litters, were used for morphologic studies. To achieve proper fixation. glutaraldehyde ( $2.5 \%)$ in cacodylate buffer $(\mathrm{pH} 7.4)$ was gently injected into the respiratory tract immediately after the decapitation of the fetus. The chest wall was then opened, and fixative was pipeted onto the exposed lungs. The lungs were removed and cut to ensure thorough fixation. After 2 days fixation, the specimens were dehydrated in an ethanol. followed by an ethanol-propylene oxide series, and finally embedded in Epon. Toluidine blue was used to stain the light microscopical sections. The sections taken for transmission electron microscopy were cut on a LKB Ultrotome (LKB-Produkter AB, Stockholm, Sweden), stained with uranyl acetate, and lead citrate and examined in a JEOL 100B transmission electron microscope (JEOL AB, Sundbyberg. Sweden).

\section{RESULTS}

\section{COURSE: AND TERMINATION OF PREGINANCY}

The MD animals exhibited continuous polyuria and glucosuria throughout pregnancy, findings that were virtually absent in the insulin-treated manifest diabetic (MDI) group. The insulin dose was not significantly altered during gestation in the MDI group and was $5.2 \pm 0.3 \mathrm{IU} /$ day $(n=15)$ at the end of pregnancy. Table I shows the blood glucose concentration of mothers and fetuses at gestational day 20. Despite the pronounced hyperglycemia in the MD group, there were no differences between the fetal serum insulin values of the N. MD, and MDI animals ( $c f$. Table 1). Table 2 shows the strikingly reduced body weight of the MD offspring as compared to the controls, whereas no significant differences between the litter sizes could be found.

\section{PHOSPHOLIPID BIOSYNTHESIS IN THE FETAL LUNG}

The biosynthesis of both PC and LPC were decreased in the lungs of the MD fetuses as compared to both the $N$ and $M D I$

Table 1. Serum glucose and serum insulin concentrations in the mothers and fetuses at gestational day 20

\begin{tabular}{|c|c|c|c|c|c|c|}
\hline \multirow[b]{3}{*}{$\mathrm{N}$} & \multirow{2}{*}{\multicolumn{2}{|c|}{$\frac{\text { MOTHER }}{\begin{array}{c}\text { glucose } \\
\text { (mmole/liter) }\end{array}}$}} & \multicolumn{4}{|c|}{ OFFSPRING } \\
\hline & & & \multicolumn{2}{|c|}{$\begin{array}{c}\text { glucose } \\
\text { (mmole/liter) }\end{array}$} & \multicolumn{2}{|c|}{$\begin{array}{l}\text { insulin } \\
(\mathrm{ng} / \mathrm{ml})\end{array}$} \\
\hline & $5.3 \pm 0.1^{1}$ & $(11)^{2}$ & $1.9 \pm 0.1$ & $(10)$ & $10.6 \pm 1.1$ & (9) \\
\hline MD & $35.6 \pm 1.2^{3}$ & (10) & $28.9 \pm 1.8^{3}$ & (10) & $10.5 \pm 1.4$ & (7) \\
\hline MDI & $6.8 \pm 1.9$ & (15) & $3.7 \pm 1.4$ & (15) & $12.9 \pm 3.1$ & (15) \\
\hline
\end{tabular}

\footnotetext{
'Mean \pm S.E.

${ }^{2}$ Numbers in parentheses, number of maternal rats or number of litters.

${ }^{3} P<0.001$ versus $\mathrm{N}$.
}

fetuses (Table 3). The MDI group, however, exhibited normal PC biosynthesis and a LPC biosynthesis, which was significantly decreased compared to the $\mathrm{N}$ group and significantly increased if compared to the MD group.

\section{MORPHOLOGIC STUDIES}

In the LM studies, the lungs of N and MDI fetuses showed developed alveolar ducts, which accounted for about $50 \%$ of the section surfaces (Fig. 1A). In contrast, the lungs of MD fetuses exhibited abundant mesenchyme and only a few completely developed alveolar ducts (Fig. $\mid B$ ). The transmission electron microscopy studies showed alveolar epithelium in the $\mathrm{N}$ and MDI fetuses, which was differentiated into type I and type II cells (Fig. $2 A$ ). This contrasted to the less well differentiated pulmonary epithelium found in the lungs of the MD fetuses (Fig. 2B). Lamellar bodies were present in the intracellular matrix in all groups, but could not be found in extracellular clusters in the MD fetuses. An apparent decrease in cytoplasmic glycogen was noticed in the MD fetuses, whereas no differences between the $\mathrm{N}$ and MDI groups were observed. Glycogen-free spaces ( $c f$. Ref. 26) tended to be larger and more numerous in the MDI group.

\section{DISCUSSION}

In diabetic pregnancy, fetal hyperinsulinemia is thought to be responsible for many of the features of diabetic fetopathia (38), including a disturbed pulmonary maturation (7). Unlike the human situation, fetal hyperinsulinemia does not appear to be a feature of severe diabetes in rats $(12,27)$. We have previously demonstrated a diminished insulin content and biosynthesis in the offspring of diabetic rats (12, 13), which may well explain the low fetal weight in the MD group because insulin is considered to be the primary growth-promoting factor during fetal life (38). In support of this hypothesis, insulin treatment readily normalized the fetal weights. The improved metabolic control in the MDI animals resulted in fetal blood glucose values about two-fold higher than those in the normal group, but without an increase in the serum insulin levels (Table 2). This experimental system. therefore, permits the study of fetal pulmonary maturation in maternal diabetes without the influence of fetal hyperinsulinemia.

In the MD group, the morphologic findings of abundant mesenchyme and only a few alveolar ducts lined with undifferentiated epithelial cells indicated a severely disturbed pulmonary maturation. This lack of pulmonary differentiation could indicate a deficient glucocorticoid action, but an antagonism between insulin

Table 2. Litter sizes and fetal body weights in the experimental groups at gestational day 20

\begin{tabular}{lrlll} 
& \multicolumn{2}{c}{ No/litter } & \multicolumn{2}{c}{ Body wt (g) } \\
\hline $\mathrm{N}$ & $14.5 \pm 1.1^{1}$ & $(11)^{2}$ & $3.5 \pm 0.1$ & $(30)$ \\
MD & $9.3 \pm 1.2$ & $(10)$ & $2.7 \pm 0.1^{3}$ & $(15)$ \\
MDI & $11.7 \pm 0.6$ & $(15)$ & $3.0 \pm 0.1$ & $(15)$ \\
\hline
\end{tabular}

${ }^{1}$ Mean \pm S.E.

2 Numbers in parentheses, number of litters

${ }^{3} P<0.001$ versus $\mathrm{N}$.

Table 3. Biosynthesis of $P C$ and LPC in the fetal rat lung at gestational day 20 expressed as pmoles $/ \mu \mathrm{g} D N A \cdot 60 \mathrm{~min}$

\begin{tabular}{llcc}
\hline & $n^{\prime}$ & PC & LPC \\
\hline N & 11 & $10.6 \pm 1.0^{2}$ & $0.245 \pm 0.44$ \\
MD & 10 & $5\left\{\begin{array}{c}6.2 \pm 0.9^{3} \\
10.0 \pm 0.5\end{array}\right.$ & $5\left\{\begin{array}{l}0.075 \pm 0.009^{4} \\
0.126 \pm 0.009^{: 1}\end{array}\right.$ \\
\hline
\end{tabular}

' $n$, number of litters.

${ }^{2}$ Mean \pm S.E.

${ }^{3} P<0.05$ versus $\mathrm{N}$.

${ }^{4} P<0.001$ versus $\mathrm{N}$

${ }^{5} P<0.001$ (MD versus $\mathrm{MDI}$ ). 


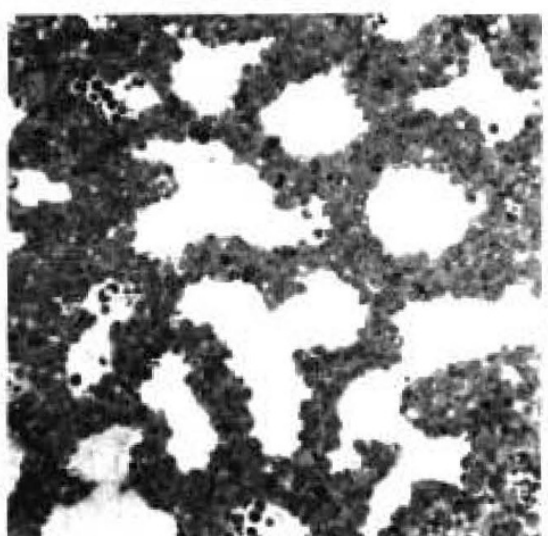

Fig. I. $A$, lung from a control rat fetus on gestational day 20 with developing alveolar duct. Original magnification, $\times 250 ; B$, lung from a

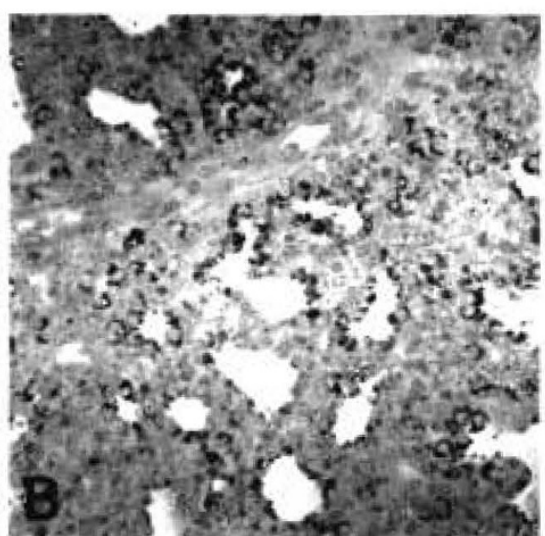

MD fetus with abundant mesenchyme and absence of developed alveolar ducts. Original magnification, $\times 250$.

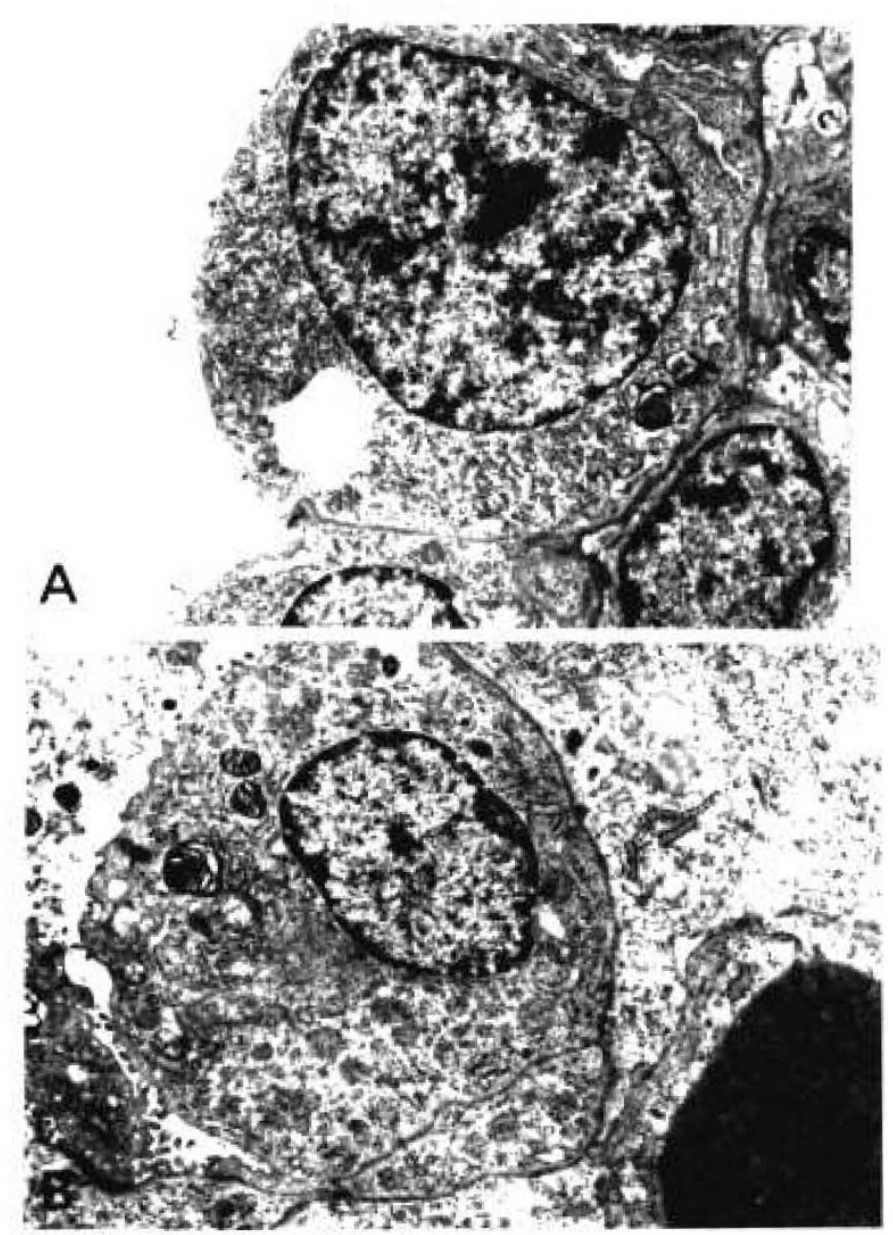

Fig. 2. A type Il cell from a control rat fetus. A basement membrane is delineating the epithelial cells from the mesenchyme. Glycogen is present as granula with characteristic glycogen free spaces. Basally, two lamellar bodies are shown. Original magnification, $\times 6600 ; B$, epithelial cell from a MD-fetus. Note microvilli, glycogen granula, and mesenchymal lipid droplet suggesting a less differentiated state. Original magnification. $\times 6600$.

and cortisol, as proposed by other investigators (10, 21, 37, 41, 43) seems unlikely, due to the absence of hyperinsulinemia in the MD offspring. The rise in fetal serum cortisol levels near term $(8,24$. 35 ) is considered to be necessary for the last part of normal lung maturation (33). The successively lowered fetal blood glucose concentration observed in the last third of normal rat and human pregnancy (12) may be of major importance in triggering this "steroid surge" $(8,18,35)$. The constant hyperglycemia in the MD fetuses could therefore remove the primary stimulus for increased glucocorticoid secretion and thus impede the normal acceleration of lung differentiation in the late gestation. In addition, a decrease in the number of glucocorticoid receptors in the rat fetal lung (4) may help to explain the delayed pulmonary maturation in diabetic pregnancy.

In normal rat pregnancy, the developing type II cells show low phospholipid and high glycogen contents before gestational day 20. However, the functionally insulinopenic MD fetuses exhibited an apparently decreased lung glycogen content and exhibited a depressed PC biosynthesis, the latter finding confirming a recent report (4) in a similar diabetic rat model. Inasmuch as glycogen is considered to be the major carbohydrate source for PC biosynthesis (34), a shortage of substrate could explain, at least in part. the decreased PC biosynthesis in the MD fetuses. Conversely. however, Gross and Smith (21) reported decreased amounts of lamellar bodies in fetal rat lung explants cultured in an excess of insulin $(1000 \mu \mathrm{U} / \mathrm{ml})$. In contrast to our in vivo model, they also found an increased pulmonary glycogen content. These authors therefore proposed that insulin, by stimulating glycogen biosynthesis, diverted carbohydrate precursors from the biosynthesis of surfactant phospholipids.

Treatment of the diabetic rats with long-acting insulin improved the metabolic control, giving a near-normal maternal blood glucose concentration. Fetal lung morphology in the MDI offspring closely resembled that of the normal rats. The disturbed PC biosynthesis was normalized, which is compatible with the idea of a restored balance between synthesis of glycogen and utilization of glycogen as a precursor for phospholipid production.

The incorporation of choline into LPC in the MDI fetuses was still only $50 \%$ of that found in the normal fetuses. The importance of LPC as an intermediate in the formation of dipalmitic PC has recently been demonstrated (1,22). The decreased activity of the LPC pathway in the MD fetuses, which could only be partly corrected by insulin treatment. may have produced surfactant with a lowered content of dipalmitic PC, i.e., with decreased surface active properties. Applied to human lung maturation in diabetic pregnancy, these findings would suggest a mechanism whereby the infant could develop RDS despite a normal lecithin/sphingomyelin ratio, an observation made repeatedly over the last decade $(6,45)$.

PG has recently been found to be decreased in the amniotic fluid of human pregnant diabetics in late gestation (6). PG may therefore be of great importance for a correct evaluation of the total surface-active properties of the fetal lung surfactant $(31,32)$.

The disturbed fetal lung maturation during pregnancy in uncontrolled. severely diabetic rats should be the subject of further investigation. Inasmuch as insulin treatment nearly normalized 
both altered phospholipid metabolism and lung morphology, attention could be directed toward a closer elucidation of the mechanisms underlying the persisting decrease in the LPC pathway and the possible role of PG biosynthesis in diabetic fetal pulmonary maturation.

\section{REFERENCES AND NOTES}

I. Abe, M., Akino. T. and Ohno, $\mathrm{K} .:$ The formation of lecithin from lysolecithin in rat lung supernatant. Biochim. Biophys. Acta. 28(1): 275. (1972).

2. Ballard. P. L., and Bailard. R. A.: Cytoplasmic receptor for glucocorticoids in lung of human fetus and neonate. J. Clin. Invest., 5.3: 477 (1974).

3. Boberg. J.: Separation of labeled plasma and tissue lipids by thin-layer chromatography. Clin. Chim. Acta. 14:325 (1966)

4. Boutwell, W. C.. and Goldman. A. S.: Depressed biochemical lung maturation and steroid uptake in an animal model of infant of diabetic mother (IDM) Pediatr. Res. 13: 355 (1979).

5. Brandstrup. N.. and Kretchmer. N.: The metabolism of glycogen in the lungs of the fetal rabbit. Dev. Biol.. 11: 202 (1965)

6. Cunningham, M. D.. Desai. N. S. Thompson. S. A.. and Greene. J. M.: Amniotic fluid phosphatidylglycerol in diabetic pregnancies. Am. J. Obstet. Gynecol. I.31: 719 (1978)

7. Draisey. T. F., Gagneja. G. L., and Thibert, R. J.: Pulmonary surfactant and amniotic fluid insulin. Obstet. Gynecol.. 50): 197 (1977).

8. Dupouy, J. P.. Coftigny, H.. and Magre, S.: Maternal and foetal corticosterone levels during late pregnancy in rats. J. Endocrinol., 65: 347 (1975).

9. Engle. M. J.. Sanders, R. L.. and Longmore, W. J.: Phospholipid composition and acyltransferase activity of lamellar bodies isolated from rat lung. Arch Biochem. Biophys. 173: 586 (1976)

10. Epstein, M. F., and Farrel, P. M.: Primate fetal lung in gestations complicated by maternal glucose intolerance. Pediatr. Res., 9: 395 (1975).

11. Epstein, M. F., and Farrel, P. M.: The choline incorporation pathway: primary mechanism for de novo lecithin synthesis in fetal primate lung. Pediatr. Res. 9: 658 (1975).

12. Eriksson. U.. Andersson. A.. Efendic. S.. Elde. R., and Hellerstrom. C.: Diabetes in pregnancy: effects on the fetal and newborn rat with particular regard to body weight, serum insulin concentration and pancreatic contents of insulin. glucagon and somatostatin. Acta Endocrinol. (in press).

13. Eriksson. U.. Andersson. A... and Hellerstrom. C.: Diabetes in pregnancy: effects on the insulin biosynthesis in the offspring of diabetic and subdiabetic rats. Acta Endocrinol. Suppl.. 227: 22 (1979)

14. Farrel. P. M.. and Blackburn. W. R.: Cortisol and lung choline phosphotransferase (CPT) activity in the fetal rat after in utero decapitation. Pediatr. Res. ? 308 (1973).

15. Fencl, M., and Tulchinsky, D.: Total cortisol in amniotic fluid and fetal lung maturation. N. Engl. J. Med., 292: 133 (1975).

16. Folch. J.. Lees. M.. and Sloane-Stanley. (i. H.: A simple method for the isolation and purification of total lipids from animal tissues. J. Biol. (hem.. 226: 497 (1957).

17. Fujiwara. T., Adams. F. H.. Sipos, S.. and El-Salawy. A.: "Alveolar" and whole lung phospholipids of the developing fetal lamb lung. Am. J. Physiol.. 215: $375(1968)$.

18. Gewolb. 1. H., Hobbins, J. C... and Tan. S. Y.: Amniotic lluid cortisol in high-risk human pregnancies. Obstet. Gynecol., 49: 466 (1977).

19. Gluck. L.. Motoyama. E. K.. Smits. H. L., and Kulovich. M. V.: The bichemical development of surface activity in mammalian lung. 1. the surface-active phospholipids: the separation and distribution of surface-active lecithin in the lungs of the developing rat fetus. Pediatr. Res. 1: 237 (1967).

20. Gluck. L.. Sribney. M., and Kulovich. M. V.: The biochemical development of surface activity in mammalian lung. II. the biosynthesis of phospholipids in the lung of the developing rabbit fetus and newborn. Pediatr. Res.. 1: 247 (1967).

21. Gross. I.. and Smith. G. J. W.: Insulin delays the morphologic maturation of fetal rat lung in vitro. Pediatr. Res., 11: 515 (1977).

22. Hallman. M.. and Raivio. K. 1.: Formation of disaturated lecithin through the lysolecithin pathway in the lung of the developing rabbit. Biol. Neonate. 27: 329 (1975).

23. Heding. L. G.: Determination of total serum insulin (IRI) in insulin-treated diabetic patients. Diabetologia. $8: 260(1972)$.
24. Herbst. J.. Wickings. E. J., Quakernack. K.. Dame, W. R., and Nieschlag. E.: Cortisol in Fruchtwasser und im mutterlichen Blut-ein Parameter zur Bestimmung der fetalen Lungenreife? Z. Geburtshilfe Perinatol.. 182: 212 (1978).

25. Hinegardner. R. T.: An improved fluorometric assay for DNA. Anal. Biochem. 39: 197 (1971)

26. Hitchcock O'Hare. K., and Sheridan. M. N.: Electron microscopic observations on the morphogenesis of the albino rat lung. with special reference to pulmonary epithelial cells. Am. J. Anat.. 127: 181 (1970).

27. Kervran. A.. Guillaume. M., and Jost. A.: The endocrine pancreas of the fetus from diabetic pregnant rat. Diabetologia. 15:387 (197x).

28. Kikkawa. Y.. Motoyama. E. K... and Cook. C. D.: The ultrastructure of the lungs of lambs. Am. J. Pathol. 47: 877 (1965)

29. Kikkawa. Y.. Motoyama, E. K.. and Giluck. L.: Study of the lungs of fetal and newborn rabbits. Am. J. Pathol.. 52: 177 (1968).

30. Kissane. J. M.. and Robins. E.: The fluorometric measurement of deoxyribonucleic acid in animal tissues with special reference to the central nervous system. J. Biol. Chem., 2.3.: 184 (1958).

31. Kulovich. M. V.. and Gluck. L.: The lung profile. II. Complicated pregnancy. Am. J. Obstet. Gynecol.. 1.35: 64 (1979)

32. Kulovich. M. V.. Hallman. M. B.. and (jluck. L.: The lung profile. I. Normal pregnancy. Am. J. Obstet. Gynecol.. 13.5: 57 (1979).

33. Liggins. G. C.: Adrenocortical-related maturational events in the fetus. Am. J. Obstet. Gynecol., 126: 931 (1976).

34. Maniscalco. W. M.. Wilson. C. M.. Gross. 1. Gobran. L.. Rooney, S. A.. and Warshaw, J. B.: Development of glycogen and phospholipid metabolism in fetal and newborn rat lung. Biochim. Biophys. Acta, 530: 333 (1978).

35. Mulay. S.. Giannopoulos. G.. and Solomon. S.: Corticosteroid levels in the mother and letus of the rabbit during gestation. Endocrinology, 43: 1342 (1973).

36. Murphy. B. E. P.: Cortisol and cortisone levels in the cord blood at delivery of infants with and without the respiratory distress syndrome. Am. J. Ohstet. Gynecol.. 119: 1112 (1974).

37. Neufeld. N. D., Sevanian. A.. Barrett. (. T... and Kaplan. S. A.: Inhibition of surfactant production by insulin in fetal rabbit lung slices. Pediatr. Res.. 13: 752 (1979).

38. Pedersen. J.: The pregnant diabetic and her newborn. Ed. 2 (Munksgaard. Copenhagen. 19771.

39. Robert, M. F.. Neff, R. K.. Hubbell, J. P.. Taeusch. H. W.. and Avery, M. E.: Association between maternal diabetes and the respiratory-distress syndrome in the newborn. N. Engl. J. Med.. 294: 357 (1976).

40. Skipski. V. P., Peterson. R. F.. and Barclay. M.: Quantitative analysis of phospholipids by thin-layer chromatography. Biochem. J.. 91: 374 (1964).

41. Smith, B. T.. Giroud. C. J. P.. Robert. M.. and Avery. M. E.: Insulin antagonism of cortisol action on lecithin synthesis hy cultured fetal lung cells. J. Pediatr.. 87: $953(1975)$

42. Sosenko, I. R., Kitzmiller. J. L. L.ow. S. W.. Blix. P.. Rubenstein. A. H. and Gabbay, K. H.: The infant of the diabetic mother. Correlation of increased cord C-peptide levels with macrosomia and hypoglycemia. N. Engl. J. Med. $301: 859(1979)$.

43. Stubbs. W. A.. and Stubbs. S. M.: Hyperinsulinism. diabetes mellitus. and respiratory distress of the newhorn: a common link? Lancet. I: 308 (1978)

44. Weinhold. P. A.: Biosynthesis of phosphatidyl choline during prenatal development of the rat lung. J. Lipid Res.. 9: 262 (1968)

45. Whitfield. C. R.. Sproule. W. B.. and Brudenell. M.: The amniotic fluid lecithin: sphingomyelin area ratio (LSAR) in pregnancies complicated by diabetes. J. Obstet. Gynaecol. Br. Common., 80): 918 (1973).

46. These results were presented in part at the 14th Annual Meeting of the Scandinavian Society for the Study of Diabetes. Oulu. Finland. June 7-9. 1979 and at the 10th Congress of the International Diabetes Federation. Vienna, Austria. September 9-14. 1979.

47. The authors wish to thank Elisabet Vennberg for expert technical assistance

48. Requests for reprints should be addressed to: Dr. Ulf Eriksson. Department of Medical Cell Biology. Biomedicum. Box 57I, S-75I 23 Uppsala. Sweden.

49. This investigation was supported by the Swedish Medical Council (Grant B8()12X-(00525-16(). The Swedish Diahetes Association. Syskonen Svensson's Fund for Medical Research. and Stiftelsen Expressen's prenatalforskningsnamnd.

50. Received for publication January 14. 1980.

51. Accepted for publication April I6. $19 \times 0$ 